University of Wollongong

Research Online

Faculty of Engineering and Information

Faculty of Engineering and Information

Sciences - Papers: Part A

Sciences

$1-1-2016$

Biodegradation of cellulose triacetate and polyamide forward osmosis membranes in an activated sludge bioreactor: observations and implications

Wenhai Luo

University of Wollongong,wl344@uowmail.edu.au

Ming Xie

Victoria University, mx504@uowmail.edu.au

Faisal I. Hai

University of Wollongong, faisal@uow.edu.au

William E. Price

University of Wollongong, wprice@uow.edu.au

Long D. Nghiem

University of Wollongong, longn@uow.edu.au

Follow this and additional works at: https://ro.uow.edu.au/eispapers

Part of the Engineering Commons, and the Science and Technology Studies Commons

Research Online is the open access institutional repository for the University of Wollongong. For further information contact the UOW Library: research-pubs@uow.edu.au 


\title{
Biodegradation of cellulose triacetate and polyamide forward osmosis membranes in an activated sludge bioreactor: observations and implications
}

\begin{abstract}
This study investigated long-term stability of forward osmosis (FO) membranes against biodegradation during prolonged exposure to activated sludge. Results show that cellulose triacetate (CTA) membranes were more resistant against biodegradation than polyamide thin film composite (TFC) ones. Nevertheless, CTA membrane biodegradation was discernible after seven months of exposure to activated sludge as manifested by an increase in the membrane average pore size, water and salt permeability, and membrane structural parameter. Asaresult, of prolonged exposure to activated sludge, the water and reverse salt fluxes of the CTA membrane increased; and concomitantly the rejection of a range of trace organic contaminants decreased significantly. The impact of prolonged exposure to activated sludge on the polyamide active layer of TFC FO membranes was even more severe. Our results indicate that currently available commercial CTA and polyamide TFC FO membranes may not be readily compatible for practical osmotic membrane bioreactor (OMBR) operation. Thus, the development of new and robust FO membrane materials specifically designed for membrane bioreactor operation is essential for commercial OMBR applications.

\section{Disciplines}

Engineering | Science and Technology Studies

\section{Publication Details}

Luo, W., Xie, M., Hai, F. I., Price, W. E. \& Nghiem, L. D. (2016). Biodegradation of cellulose triacetate and polyamide forward osmosis membranes in an activated sludge bioreactor: observations and implications. Journal of Membrane Science, 510 284-292.
\end{abstract}




\title{
Biodegradation of cellulose triacetate and polyamide forward osmosis membranes in an activated sludge bioreactor: Observations and Implications
}

\author{
Revised manuscript submitted to Journal of Membrane Science
}

January 2016

\footnotetext{
Wenhai Luo ${ }^{\text {a }}$, Ming Xie ${ }^{\text {b }}$, Faisal I. Hai ${ }^{\text {a }}$, William E. Price ${ }^{c}$, Long D. Nghiem ${ }^{\text {a, }}{ }^{*}$

a Strategic Water Infrastructure Laboratory, School of Civil, Mining and Environmental Engineering, University of Wollongong, Wollongong, NSW 2522, Australia

${ }^{\mathrm{b}}$ Institute for Sustainability and Innovation, College of Engineering and Science, Victoria University, Melbourne, VIC 8001, Australia

c Strategic Water Infrastructure Laboratory, School of Chemistry, University of Wollongong, Wollongong, NSW 2522, Australia
}

\footnotetext{
*Corresponding author: longn@uow.edu.au; Ph: +61 (2) 42214590.
} 


\begin{abstract}
This study investigated long-term stability of forward osmosis (FO) membranes toward biodegradation due to prolonged exposure to activated sludge. Results show that cellulose triacetate (CTA) membranes were more persistent against biodegradation in comparison with polyamide thin film composite (TFC) ones. Nevertheless, CTA membrane biodegradation was discernible after seven months of exposure to activated sludge as manifested by an increase in the membrane average pore size, water and salt permeability, and membrane structural parameter. As a result, due to prolonged exposure to activated sludge, the water and reverse salt fluxes of the CTA membrane increased; and concomitantly the rejection of a range of trace organic contaminants decreased significantly. The impact of prolonged exposure to activated sludge on the polyamide active layer of TFC FO membranes was even more severe. Our results indicate that current commercially available CTA and polyamide TFC FO membranes may not be readily compatible for practice osmotic membrane bioreactor (OMBR) operation. Thus, the development of new and robust FO membrane materials specifically designed for membrane bioreactor operation is essential for commercial OMBR applications.
\end{abstract}

Keywords: Forward osmosis; membrane stability; cellulose triacetate; polyamide; osmotic membrane bioreactor. 


\section{Introduction}

A current major challenge is to provide adequate access to clean water to everyone in the world [1]. This grand challenge calls for the development of new and innovative water treatment technologies that are robust, versatile, and energy efficient. One such promising technology is osmotic membrane bioreactor (OMBR), which combines the activated sludge treatment process with forward osmosis (FO) for water purification [2-5].

By employing a selective, polymeric FO membrane, contaminants can be effectively retained in the bioreactor for further biodegradation during OMBR operation [6]. OMBR can significantly enhance the treatment of various trace organic contaminants (TrOCs) [6-9]. TrOCs are a diverse range of emerging organic chemicals of either anthropogenic or natural origin. Given their ubiquitous occurrence in reclaimed water, TrOCs are of particular concern to potable water reuse [7].

OMBR is operated at a negligible hydraulic pressure. Thus, membrane fouling is less severe and more reversible than conventional MBR systems using either microfiltration (MF) or ultrafiltration [2,10]. OMBR can potentially be used as a stand-alone process to extract treated water for osmotic dilution [11], or integrated with other processes, such as membrane distillation (MD) [12] and nanofiltration (NF) or reverse osmosis (RO) [13-15], to recover the draw solute and produce clean water. In particular, coupling OMBR with MD can be an energy-efficient option as it allows for the utilisation of solar thermal or waste heat.

FO, an osmosis-driven membrane process, finds a wide range of applications in seawater desalination and water reclamation [16, 17]. Early FO studies using membranes designed for RO applications did not yield any promising results due to severe internal concentration polarisation (ICP). ICP is an inherent phenomenon associated with the thick supporting layer of commercially available RO membranes [18]. Indeed, most research progress in current FO applications and exploration of new applications can be attributed to the development of improved semi-permeable membranes as well as novel techniques to fabricate FO membranes [19-21]. Recently reported FO membranes can achieve high water flux and salt rejection with minimal ICP and excellent mechanical strength. The potential to include recent advances in material science and novel chemistries can further enhance the performance of FO membranes [22].

FO membranes currently available in the market include asymmetric cellulose triacetate (CTA) and polyamide thin-film composite (TFC) materials. CTA membranes used in most 
recent FO and OMBR studies are from Hydration Technology Innovations (HTI). These membranes consist of a CTA active layer embedded with a thin polyester mesh for mechanical support [18]. The hydrophilic nature of cellulose renders these membranes readily wettable. Thus, CTA FO membranes can simultaneously achieve high water permeability and excellent fouling resistance [23]. Recent development of new membrane materials has resulted in the fabrication and commercialisation of polyamide TFC membranes. TFC FO membranes comprise a thin, selective polyamide active layer on a porous supporting layer and have been reported to show higher water permeability and solute rejection capacity in comparison with CTA membranes [24-26]. The thin and highly porous supporting layer of CTA and TFC FO membranes considerably reduces the ICP encountered for commercial RO membranes in FO applications [18, 27].

Despite the efforts in the development and commercialisation of FO membranes, little is known about their stability during long-term OMBR operation. It has been well established that cellulose-based membranes can be susceptible to biodegradation and hydrolysis [28-30]. Choi et al. [29] evaluated the stability of a cellulose acetate NF membrane used in an NF membrane bioreactor and reported notable decrease in product water quality possibly due to membrane biodegradation after over 250 days of continuous operation. In a more recent study, Chen et al. [5] observed a sudden increase in the mixed liquor salinity (over 20 times) when a CTA FO membrane was used to extract treated water from an anaerobic bioreactor for over 76 days. They attributed this observation to membrane biodegradation or hydrolysis in the bioreactor, although no clear evidence was provided to verify this hypothesis. Compared to CTA membranes, it was suggested that polyamide TFC membranes might be more resistant to biodegradation and hydrolysis [31, 32]. Nevertheless, biomass in the activated sludge, such as strains of Pseudomonas sp., has been reported to degrade polyamides by producing extracellular enzymes that hydrolyse amide bonds [33]. To date, a systematic investigation of the stability of polyamide FO membranes against biodegradation due to prolonged exposure to activated sludge has not been reported.

This study aims to investigate long-term stability of FO membranes against biodegradation caused by prolonged exposure to activated sludge. Both commercially available CTA and TFC FO membranes were exposed to an activated sludge bioreactor (integrated with an MF membrane for water purification) for a prolonged period. Key properties of FO membranes were compared before and after prolonged exposure to activated sludge. Membrane performance was also examined by analysing the rejection of TrOCs and its associated 
mechanisms in FO applications. The results will have important implications for understanding FO membrane stability during long-term OMBR operation and developing novel membrane materials to enhance the system sustainability.

\section{Materials and methods}

\subsection{Forward osmosis membranes}

Flat-sheet CTA and TFC FO membranes from HTI (Albany, OR) were used in this study. The CTA membrane was composed of a cellulose triacetate layer with an embedded woven supporting mesh, which is fabricated via a phase inversion method [18]. The TFC membrane comprised a thin, selective polyamide active layer on the top of a porous polysulfone supporting layer via an interfacial polymerisation process [25].

\subsection{Forward osmosis and reverse osmosis systems}

A bench-scale FO system was used to evaluate the membrane performance before and after prolonged exposure to activated sludge. The FO system comprised a cross-flow membrane cell and a draw solution delivery and control unit (Figure S1a, Supplementary Data). The membrane cell was made of acrylic plastic and had two identical flow chambers with length, width, and height of 130, 95, and $2 \mathrm{~mm}$, respectively. The effective membrane area was

$123.5 \mathrm{~cm}^{2}$. Two gear pumps (Micropump, Vancouver, WA) were used to simultaneously circulate the feed and draw solutions to the membrane cell at a cross-flow velocity of $9 \mathrm{~cm} / \mathrm{s}$. The draw solution reservoir was placed on a digital balance connected to a computer to determine the water flux of the FO membrane. The draw solution concentration was kept constant in each FO experiment using conductivity control equipment. A detailed description of the conductivity control unit is available elsewhere [9].

A bench-scale RO system with a stainless steel cross-flow membrane cell was used for membrane characterisation (Figure S1b, Supplementary Data). The membrane cell had a flow channel height of $0.2 \mathrm{~cm}$ and an effective membrane area of $40 \mathrm{~cm}^{2}(4 \mathrm{~cm} \times 10 \mathrm{~cm})$. A Hydra-Cell pump (Wanner Engineering, Minneapolis, MN) was used to pressurise the feed solution to the membrane cell. Hydraulic pressure and cross-flow velocity were regulated by a back-pressure regulator and a bypass valve. A temperature controller unit (Neslab RTE7, Waltham, MA) equipped with a stainless steel heat exchanger coil was used to maintain the feed solution temperature of $22 \pm 1^{\circ} \mathrm{C}$. Permeate flux was monitored by a digital flow meter (Optiflow, Palo Alto, CA) connected to a computer.

\subsection{Membrane exposure to activated sludge}


Membrane exposure to activated sludge was simulated by mounting the CTA and TFC membrane samples onto stainless steel frames and suspending them in an MBR equipped a hollow fibre MF membrane module (Mitsubishi Rayon Engineering, Tokyo, Japan) (Figure S2, Supplementary Data). FO membrane samples were suspended vertically and parallel to the MF membrane module. Thus, they were also subjected to air scouring. However, there was no water permeation through the FO membranes. A synthetic wastewater (Table S1, Supplementary Data) was used to feed the MBR. Basic characteristics of the synthetic wastewater and operational conditions of the MBR are summarised in Tables S2 and S3 of Supplementary Data, respectively. Biological stability of the MBR was periodically monitored by measuring the bulk organic removal, biomass concentration, and sludge specific oxygen uptake rate.

The exposure protocol in this study may differ from that in real OMBR operation, where water is permeated through the membrane. However, because bacteria cannot penetrate into the FO membrane in both cases, microbial degradation can only occur on the membrane surface. More importantly, our exposure protocol eliminates any variation resulted by the water flux, thus allowing for a systematic and comparable assessment of the biodegradation of FO membranes in active biomass.

Membrane samples were thoroughly rinsed with Milli-Q water to remove attached biomass after exposure to activated sludge for three and seven months (denoted as the $\operatorname{Exp}_{3 \mathrm{~m}}$ and $E_{7 m}$ membranes, respectively). Both the pristine and exposed membranes were stored with Milli-Q water at $4{ }^{\circ} \mathrm{C}$ before membrane characterisation and TrOC rejection experiments.

\subsection{Membrane characterisation}

\subsubsection{Membrane surface morphology and functional groups}

Membrane surface morphology was characterised using a scanning electron microscopy (SEM) (JEOL JCM-6000, Tokyo, Japan). Prior to the SEM measurement, air-dried membrane samples were coated with an ultra-thin layer of gold using a sputter coater (SPI Module, West Chester, PA).

Membrane surface functional groups were identified using an Attenuated Total ReflectionFourier Transform Infrared (ATR-FTIR) spectroscopy (IRAffinity-1, Shimadzu, Kyoto, Japan). Absorbance spectra were measured with 20 scans of each sample at a spectral resolution of $2 \mathrm{~cm}^{-1}$. A background correction was conducted before each measurement.

\subsubsection{Membrane transport parameters}


Key membrane transport parameters were characterised following a protocol previously reported by Cath et al. [25]. The pure water permeability coefficient $(A)$ and salt $(\mathrm{NaCl})$ permeability coefficient $(B)$ of the membrane active layer were determined using the crossflow RO system described above. The $A$ and $B$ values were measured using deionised water and 2,000 mg/L $\mathrm{NaCl}$ solution as the feed solution, respectively. The RO system was stabilised for two hours at an applied hydraulic pressure $(\Delta P)$ of 10 bar and a cross-flow velocity of $25 \mathrm{~cm} / \mathrm{s}$ before recording the water flux with deionised water $\left(J_{R O}\right)$ and that with the $\mathrm{NaCl}$ solution $\left(J_{\mathrm{NaCl}}\right)$. In the experiments measuring the $B$ value, feed and permeate samples were collected to determine the observed $\mathrm{NaCl}$ rejection $\left(R_{o b}\right)$. The $A$ and $B$ values were calculated as follows:

$$
\begin{aligned}
& A=\frac{J_{R O}}{\Delta P} \\
& B=J_{N a C l}\left(\frac{1-R_{o b}}{R_{o b}}\right) \exp \left(-\frac{J_{N a C l}}{k_{f}}\right)
\end{aligned}
$$

where $k_{f}$ is the mass transfer coefficient of the cross-flow RO membrane cell [25].

The mass transfer coefficient $\left(k_{f}\right)$ was determined using the salt concentration at the membrane surface with the thin-film theory for concentration polarisation [26, 34, 35]:

$$
k_{f}=\frac{J_{\mathrm{NaCl}}}{\ln \left[\frac{\Delta P}{\pi_{b}-\pi_{p}}\left(1-\frac{J_{\mathrm{NaCl}}}{J_{R O}}\right)\right]}
$$

where $\pi_{p}$ and $\pi_{b}$ are the feed and permeate osmotic pressures, respectively, which can be determined by their corresponding salt concentrations based on the van’t Hoff equation.

The membrane structural parameter $(S)$ determines the degree of ICP and is defined as:

$$
S=\frac{l \tau}{\varepsilon}
$$

where $l$ is the supporting layer thickness, $\tau$ is the supporting layer tortuosity, and $\varepsilon$ is the supporting layer porosity.

In this study, the $S$ value was experimentally determined using the cross-flow FO system mentioned above with a $0.5 \mathrm{M} \mathrm{NaCl}$ draw solution and deionised water feed solution. The membrane active layer was in contact with the feed solution (i.e. FO mode). The FO system 
was stabilised for one hour before recording the water flux $\left(J_{F O}\right)$ to determine the $S$ value using [25, 36]:

$$
S=\frac{D_{s}}{J_{F O}} \ln \left(\frac{B+A \pi_{D, b}}{B+J_{F O}+A \pi_{F, m}}\right)
$$

where $D_{s}$ is the bulk solution diffusivity of the draw solute; $\pi_{D, b}$ is the bulk osmotic pressure of the draw solution; and $\pi_{F, m}$ is the osmotic pressure at the membrane surface on the feed side (zero for deionised water feed).

\subsubsection{Membrane average pore radius}

Erythritol, xylose, and glucose obtained from Sigma-Aldrich (Saint Louis, MO) were used as the reference organic solutes to estimate the average pore radius of the membrane active layer using the cross-flow RO system based on a protocol reported previously by Xie et al. [26]. These three organic solutes are inert, neutrally charged, and do not adsorb to the membrane [37]. These reference solutes were dissolved individually in deionised water to obtain a concentration of $40 \mathrm{mg} / \mathrm{L}$ (as total organic carbon (TOC)). The membrane was precompacted for one hour at a hydraulic pressure of 18 bar and a cross-flow velocity of $25 \mathrm{~cm} / \mathrm{s}$ before the RO filtration experiments at 8, 10, 12, 14, and 16 bar. After stabilising the RO system for one hour at each hydraulic pressure, feed and permeate samples were collected for TOC analysis.

The membrane average pore radius was calculated based on the pore hindrance transport model described by Nghiem et al. [35]. In this model, the FO membrane was considered as a bundle of cylindrical capillary tubes with the same radius. In addition, the entrance of the spherical solute particles to the membrane pores was assumed to be random. It is noteworthy that the pore hindrance model was developed for neutral and non-adsorptive solutes. Thus, it may underestimate the rejection of charged organic solutes and overestimate the rejection of hydrophobic organic solutes [26].

In the pore hindrance transport model, the ratio of solute radius $\left(r_{s}\right)$ to the membrane pore radius $\left(r_{p}\right), \lambda=r_{s} / r_{p}$, is related by the distribution coefficient for hard-sphere particles $(\varphi)$ when only steric interactions are considered:

$\varphi=(1-\lambda)^{2}$

The real (or intrinsic) rejection of the reference organic solutes $\left(R_{\text {real }}\right)$ by the FO membranes was determined from: 
$R_{\text {real }}=1-\frac{C_{L}}{C_{O}}=1-\frac{\varphi K_{c}}{1-\exp \left(-P_{e}\right)\left(1-\varphi K_{c}\right)}$

where $C_{o}$ and $C_{L}$ are the solute concentrations just outside the pore entrance (i.e. on the membrane surface in the feed side) and pore exit (i.e. on the membrane surface in the permeate side), respectively; $\varphi$ is the distribution coefficient for hard-sphere particles when only steric interactions are considered; $K_{c}$ is the hydrodynamic hindrance coefficient for convection; and $P_{e}$ is the membrane Peclet number, which can be defined as:

$P_{e}=\frac{K_{c} J_{r} l_{a}}{K_{d} D}=\frac{K_{c} J_{v} l_{a}}{K_{d} D \varepsilon_{a}}$

where $K_{d}$ is the hydrodynamic hindrance coefficient for diffusion; $J_{r}$ is the radial average fluid velocity in a cylindrical membrane pore, which is equal to the membrane volumetric permeate flux $\left(J_{v}\right)$ divided by the effective porosity of the membrane active layer $\left(\varepsilon_{a}\right)$; $D$ is the Stokes-Einstein diffusion coefficient, $l_{a}$ is the theoretical pore length (i.e. the thickness of the membrane active layer). A detailed calculation of $P_{e}, K_{c}$ and $K_{d}$ has been described elsewhere [35, 38].

By applying the thin-film theory for concentration polarisation, the real rejection $\left(R_{\text {real }}\right)$ in Eq. (6) can be calculated from the observed rejection $\left(R_{o b}\right)$, which is determined based on different TOC concentrations between the feed and permeate samples:

$\ln \frac{\left(1-R_{\text {real }}\right)}{R_{\text {real }}}=\ln \left(\frac{1-R_{o b}}{R_{o b}}\right)-\frac{J_{v}}{k_{f}}$

where $k_{f}$ is the mass transfer coefficient as defined in Eq. (3).

\subsubsection{Membrane surface charge and hydrophobicity}

Membrane surface charge was measured using a SurPASS electrokinetic analyser (Anton Paar CmbH, Graz, Austria). Zeta potential of the membrane surface was calculated from the measured streaming potential using the Fairbrother-Maastin approach [39]. All streaming potential measurements were performed in a background electrolyte solution (10 $\mathrm{mM} \mathrm{KCl})$. The background solution was also used to thoroughly flush the cell before $\mathrm{pH}$ titration using either hydrochloric acid $(0.5 \mathrm{M})$ or potassium hydroxide $(0.5 \mathrm{M})$. All measurements were conducted in a temperature-controlled room $\left(22 \pm 1^{\circ} \mathrm{C}\right)$.

Membrane hydrophobicity was evaluated by contact angle measurements using a Rame-Hart Goniometer (Model 250, Rame-Hart, Netcong, NJ) based on the standard sessile drop 
method. Prior to the measurement, membrane samples were air-dried in a desiccator. Ten water droplets were applied to each membrane sample and contact angles on both sides of the droplet were analysed.

\subsection{Trace organic contaminant rejection experiment}

Membrane performance was evaluated by analysing the rejection of 24 TrOCs, which have been ubiquitously detected at trace level in municipal wastewater. Key properties of these TrOCs, including hydrophobicity, molecular weight, and functional groups, are summarised in Table S4 of Supplementary Data. A stock solution containing $25 \mu \mathrm{g} / \mathrm{mL}$ of each TrOC was prepared in pure methanol and stored at $-18{ }^{\circ} \mathrm{C}$ in the dark.

TrOC rejection experiments were performed using the bench-scale FO system with the membrane active layer facing the feed solution (i.e. FO mode). A background electrolyte solution (20 mM NaCl and $1 \mathrm{mM} \mathrm{NaHCO}_{3}$ ) and a $1 \mathrm{M} \mathrm{NaCl}$ solution were used as the feed and draw solution, respectively. The TrOC stock solution was added to the feed solution to obtain a concentration of $5 \mu \mathrm{g} / \mathrm{L}$ of each compound. The initial volumes of the feed and draw solutions were 4 and $1 \mathrm{~L}$, respectively. All experiments were conducted in a temperaturecontrolled room $\left(22 \pm 1^{\circ} \mathrm{C}\right)$ and concluded when $1 \mathrm{~L}$ water permeated through the $\mathrm{FO}$ membrane (i.e. 25\% water recovery). Samples were collected from both the feed and draw solutions at the beginning and conclusion of each FO experiment for TrOC analysis.

TrOC concentrations in the feed and draw solutions were analysed based on an analytical method described by Hai et al. [40]. Briefly, this method involved solid phase extraction, derivatisation, and quantification by a gas chromatography-mass spectrometry (GC-MS) system (QP5000, Shimadzu, Kyoto). Since the product water was diluted by the draw solution in the FO process, a dilution factor $(D F)$ was introduced to determine the permeate TrOC concentrations:

$$
D F=\frac{V_{D S}}{V_{F O}}
$$

where $V_{D S}$ was the total volume of the draw solution at the conclusion of each experiment; and $V_{F O}$ was the volume of water permeated through the FO membrane.

Therefore, TrOC rejection by the FO membrane was defined as:

$$
R=\left(1-\frac{C_{D S}}{C_{F S}} D F\right) \times 100
$$


where $C_{D S}$ was the measured TrOC concentrations in the draw solution at the conclusion of each experiment; and $C_{F S}$ was the measured TrOC concentrations in the feed solution at the beginning of each experiment.

\section{Results and discussion}

\subsection{Membrane degradation by activated sludge}

\subsubsection{Membrane surface morphology}

Notable changes in the surface morphology of both CTA and TFC membranes were observed after prolonged exposure to activated sludge (Figures 1 and 2). SEM analysis after seven months of exposure revealed many sphere-like indents on the CTA membrane surface (Figure 1). This observation could be attributed to the biodegradation of the CTA surface [30]. Biofilm tends to create non-uniform surface conditions with different microbial colonies [41]. Subsequently, attack might start at some points on the membrane surface, leading to localised degradation, similar to the formation of pitting often seen in metal corrosion caused by bacteria [42].

\section{[Figure 1]}

Exposure to activated sludge resulted in more severe damage to TFC membranes in comparison with CTA ones (Figure 2). This observation was possibly due to the different materials and structures of these membranes (section 2.1). After three months of exposure, the polyamide active layer of the TFC membrane was severely worn down. This observation is different from that reported by Choi et al. [32] who compared the performance of the hollow fibre CTA and polyamide NF membranes in an NF membrane bioreactor. In their study, severe biodegradation of CTA NF membranes was demonstrated by an increase in the water flux and a decrease in the product water quality; while stable performance of polyamide NF membranes was observed over 250 days of continuous operation. Both CTA and TFC membrane modules were wrapped with nylon fabric in their study to prevent membrane materials from direct exposure to activated sludge. Thus, the excessive damage to the membrane polyamide layer observed in this study was possibly the result of biodegradation caused by direct and prolonged exposure to activated sludge. Yamano et al. [33] also reported that biomass in the activated sludge, such as strains of Pseudomonas sp., could secrete extracellular enzymes to hydrolyse amide bonds and therefore degrade polyamides. Nevertheless, further investigation is required to identify microbial species that are responsible for membrane degradation in activated sludge. Another plausible reason for 
such severe damage is membrane abrasion by sludge particles under air scouring conditions. Indeed, polyamide debris was observed in the mixed liquor during membrane exposure. As a result, TFC membrane samples were excluded from subsequent FO and RO filtration experiments for determining membrane transport parameters (i.e. $A, B$ and $S$ ), average pore radius, and TrOC rejection.

\section{[Figure 2]}

\subsubsection{Membrane transport properties}

Key transport parameters of the pristine and exposed CTA membranes are summarised in Table 1. The exposed membranes (i.e. $\operatorname{Exp}_{3 \mathrm{~m}}$ and $\operatorname{Exp}_{7 \mathrm{~m}}$ samples) exhibited a higher pure water permeability coefficient $(A)$ and salt $(\mathrm{NaCl})$ permeability coefficient $(B)$ than the pristine membrane. The observed increase in both $A$ and $B$ values can be attributed to the enlargement in the membrane average pore radius after prolonged exposure to activated sludge (Table 2). As a result, a much higher initial water flux and reverse salt ( $\mathrm{NaCl})$ flux were observed in FO applications with the exposed membranes (Figure S3 and Table S5, Supplementary Data). It is noteworthy that the $\operatorname{Exp}_{7 \mathrm{~m}}$ membrane (exposed to activated sludge for seven months) experienced a considerable flux decline at the beginning of FO operation (Figure S3, Supplementary Data). This result was possibly due to the rapid salinity increase in the feed solution caused by the excessive reverse salt ( $\mathrm{NaCl})$ flux (Table S5, Supplementary Data) associated with the high water permanence at the beginning of FO operation. In addition, the initial rearrangement of the polymeric matrix of the membrane active skin layer may also contribute to the observed flux decline. It has been reported that the reverse salt flux could increase the ionic strength within the interface between the membrane active layer and the feed solution, reducing the electrostatic repulsion among CTA polymer chains and thereby compacting the membrane active layer [43].

\section{[TABLE 1]}

The membrane structural parameter $(S)$ determines the severity of ICP and is defined as the product of the thickness $(l)$ and tortuosity $(\tau)$, divided by the porosity $(\varepsilon)$ (i.e. $S=l \tau / \varepsilon$ ) of the membrane supporting layer [25]. In this study, the $S$ value was experimentally determined in FO operation with a $0.5 \mathrm{M} \mathrm{NaCl}$ draw solution and deionised water feed solution (section 2.4). As shown in Table 1, the $\operatorname{Exp}_{7 \mathrm{~m}}$ membrane had the highest $S$ value, followed by the $\operatorname{Exp}_{3 \mathrm{~m}}$ and the pristine membranes, respectively. This result could be ascribed to the swelling of the polymer supporting layer after prolonged exposure to activated sludge, which likely 
increased the tortuosity and decreased the porosity of the membrane supporting layer [24]. Nevertheless, it should be noted that the severe reverse salt flux of the $\operatorname{Exp}_{7 m}$ membrane (Table S5, Supplementary Data) could gradually increase the osmotic pressure at the membrane surface on the feed side in FO operation. Thus, the $S$ value of the $\operatorname{Exp}_{7 \mathrm{~m}}$ membrane could be slightly overestimated using the empirical model delineated in Eq. 5 (section 2.4). In addition, exposure to activated sludge significantly increased the membrane $A$ and $B$ values, which may in turn affect the $S$ value calculation for the exposed membranes [44].

\subsubsection{Average membrane pore radius}

The rejection of each reference organic solute by the pristine and exposed CTA membranes at different permeate fluxes was determined to estimate the membrane pore radius based on the membrane pore hindrance transport model (Figure S4, Supplementary Data). The real rejection $\left(R_{\text {real }}\right)$ was obtained from the observed rejection by accounting for concentration polarisation effects (equation 9, section 2.4) and the mass transfer coefficient (equation 3, section 2.4). In the pore hindrance transport model, $\varphi K_{c}$ and $P_{e} / J_{v}$ are uniquely related to the real rejection $\left(R_{\text {real }}\right)$ and could be determined by fitting the real rejection data to the model (equation 7, section 2.4) using an optimisation procedure (Solver, Microsoft Excel). In addition, $\varphi K_{c}$ and $P_{e} / J_{v}$ are also a sole function of the variable $\lambda$, which is the ratio of solute radius $\left(r_{s}\right)$ to the membrane pore radius $\left(r_{p}\right)$. Therefore, the membrane pore radius was determined from the $\lambda$ value for each reference organic solute and summarised in Table 2.

\section{[TABLE 2]}

For each membrane, a small standard deviation was observed for the membrane pore radii obtained from these three reference organic solutes (Table 2). Thus, the average membrane pore radius was calculated for the pristine and exposed membranes. Compared to the pristine membrane, the membrane pore radius increased marginally after three months of exposure to activated sludge. On the other hand, a notable pore radius enlargement was observed for the membrane exposed to activated sludge for seven months (i.e. the $\operatorname{Exp}_{7 \mathrm{~m}}$ sample). The estimated membrane pore radii are also in good agreement with membrane mass transport parameters (Table 1), where the $\operatorname{Exp}_{7 \mathrm{~m}}$ membrane exhibited the highest $A$ and $B$ values, followed by the $\operatorname{Exp}_{3 m}$ and pristine membranes, respectively.

\subsubsection{Membrane chemical properties}

Surface functional groups of the pristine and exposed CTA and TFC membranes were characterised by ATR-FTIR (Figures 3 and 4). The pristine CTA membrane was 
characterised by typical absorbance peaks at wavenumber of $1740 \mathrm{~cm}^{-1}$ (ester $\mathrm{C}=\mathrm{O}$ stretching in cellulose triacetate), and 1366, 1214, and $1031 \mathrm{~cm}^{-1}$ (C-O stretching in hydroxyl functional group) (Figure 3). Similar ATR-FTIR spectra were also observed for the exposed membranes (both $\operatorname{Exp}_{3 \mathrm{~m}}$ and $\operatorname{Exp}_{7 \mathrm{~m}}$ samples), which indicated that biodegradation occurred in some points of the CTA surface did not completely modify functional groups of the membrane active layer. Wang et al. [45] also reported that no clear changes in the FO membrane active layer were observed from FTIR spectra, although the membrane water and solute permeability was increased after exposure to chemical cleaning reagents. They attributed the changes in membrane transport parameters to the reaction between chemical agents and polymeric materials in the inner structure of FO membranes based on the confocal laser scanning microscope imaging. However, in an OMBR operation, microbes cannot enter the membrane interface due to the high retention of biomass by the FO membrane. In addition, water permeation through the support layer [46] and high salinity draw solution are unfavourable conditions for microbial attachment and subsequent biodegradation. Further investigation is needed to elucidate variations in the membrane inner structure and thus better understand membrane stability in OMBR operation.

\section{[FIGURE 3]}

ATR-FTIR spectra of the pristine and exposed TFC membranes suggested that membrane damage after exposure to activated sludge was mainly due to physical scouring under air scouring conditions. The active layer (i.e. polyamide layer) of the pristine TFC membrane exhibited its distinctive amide bands at wavenumbers of 1778 and $1719 \mathrm{~cm}^{-1}$ (symmetric and asymmetric $\mathrm{C}=\mathrm{O}$ stretching, respectively), $1378 \mathrm{~cm}^{-1}$ (C-N-C stretching), and $1110 \mathrm{~cm}^{-1}$ (amide ring) (Figure 4a). In addition, the membrane active layer also showed a broad peak at wavenumber of $3300 \mathrm{~cm}^{-1}$ (O-H stretching) and a sharp peak at $2967 \mathrm{~cm}^{-1}$ (C-H stretching), which indicated the presence of carboxylic functional groups on the membrane surface. Due to severe regional damage to exposed TFC membranes, membrane coupons with and without polyamide debris after seven months of continuous exposure were cut for ATR-FTIR analysis and denoted as active layer 1 and 2, respectively (Figure 4b and c). Consistent absorbance spectra were observed for the active layer 1 of the exposed membrane and the active layer of the pristine membrane. This result suggests that membrane degradation did not change polyamide functional groups. On the other hand, physical scouring abraded the polyamide layer and resulted in the exposure of the polysulfone layer, as indicated by the similar 
absorbance spectra between the active layer 2 of the exposed membrane and the supporting layer of the pristine membrane (Figure $4 \mathrm{c}$ and $\mathrm{d}$ ).

\section{[FIGURE 4]}

Zeta potential and contact angle measurements were only conducted for CTA membrane samples because of excessive damage to TFC membranes. Zeta potential analysis suggested that prolonged exposure to activated sludge did not significantly affect the surface charge of the membrane active layer (Figure 5). This result is in good agreement with ATR-FTIR measurements, where negligible difference in surface functional groups was observed between the pristine and exposed CTA membranes (Figure 3). Hydroxyl is the predominant functional group on the CTA membrane surface and can be deprotonated at high solution $\mathrm{pH}$ $[26,47]$. Thus, both the pristine and exposed CTA membranes became more negatively charged as the solution $\mathrm{pH}$ increased (Figure 5). Compared to the pristine membrane, a slightly lower zeta potential was observed for the exposed membranes at high solution $\mathrm{pH}$. The reason for this was not clear, but may be due to the preferential adsorption of anions, such as hydroxide and chloride, onto the exposed membrane surface with incompletely rinsed microbial products. The presence of microbial residues on the membrane surface might also result in a small but discernible increase in the membrane hydrophobicity as manifested by higher contact angles of the exposed membranes in comparison with the pristine sample (Table 3).

\section{[FIGURE 5]}

\section{[TABLE 3]}

\subsection{Rejection of trace organic contaminants}

Physiochemical properties (e.g. molecular weight, hydrophobicity, and surface charge) of TrOCs play an important role in their rejection by the FO membrane $[26,48]$. Of the 24 TrOCs investigated here, 16 compounds are non-ionic, seven are negatively charged, and amitriptyline is positively charged at pH 8 (i.e. feed solution pH) (Figure 6). Based on their effective octanol-water partition coefficient $(\log D)$ at solution $\mathrm{pH}$ 8, the 16 non-ionic TrOCs could be further classified as hydrophobic (i.e. $\log D>3.2$ ) and hydrophilic (i.e. $\log D<$ 3.2) [49].

\section{[FIGURE 6]}


The pristine CTA membrane exhibited excellent capacity for TrOC rejection, with rejection rates between 80 and 100\% (Figure 6). This result is consistent with that reported previously $[26,48,50]$. In general, the rejection of charged TrOCs was consistently above 95\%, while variable rejections were observed for non-ionic compounds. The high rejection of charged TrOCs can be attributed to the synergy between steric hindrance and electrostatic repulsion arising from their hydrated molecular dimension and the negative surface charge of the CTA membrane [26]. The hydrated radii of charged TrOCs in aqueous solution are significantly larger than their apparent ionic radii, thereby increasing their membrane retention through steric hindrance [51].

The rejection of non-ionic TrOCs is largely controlled by steric hindrance and hydrophobic hydrophilic force between solutes and the membrane [48]. It has been reported that an initial adsorption but subsequent partition and diffusion of non-ionic hydrophobic TrOCs through the membrane may reduce their rejection in the FO process [52]. In this study, all seven nonionic hydrophobic TrOCs were effectively rejected by the pristine CTA membrane and the rejection increased corresponding to their molecular weight (Figure 6). The high rejection of these hydrophobic compounds could be ascribed to the relatively short experiment (i.e. 8 - 10 hours), whereby their diffusion across the membrane polymer matrix might be negligible [48]. By contrast, no clear correlation between the rejection and molecular weight was observed for non-ionic hydrophilic TrOCs (Figure 6). This observation was possibly due to the different molecular shapes and dipole moments of these hydrophilic compounds [53].

Prolonged exposure to activated sludge reduced the CTA membrane capacity for TrOC rejection (Figure 6). Compared to the pristine membrane, the exposed membranes (particularly the $\operatorname{Exp}_{7 \mathrm{~m}}$ sample) had a lower rejection for all 24 TrOCs investigated in this study. This result is consistent with the substantial increase in the salt $(\mathrm{NaCl})$ permeability coefficient of the exposed membranes (Table 1), both of which could be attributed to the enlargement in membrane pore radii after prolonged exposure to activated sludge (Table 2). Nevertheless, with an exception of diclofenac and estriol, no discernible difference between the pristine and exposed membranes (both the $\operatorname{Exp}_{3 \mathrm{~m}}$ and $\operatorname{Exp}_{7 \mathrm{~m}}$ samples) was observed for the rejection of TrOCs with molecular weight above $270 \mathrm{~g} / \mathrm{mol}$.

\section{Conclusion}

Results reported here demonstrate that CTA FO membranes are more resistant to biodegradation caused by prolonged exposure to activated sludge compared to polyamide 
TFC FO membranes. Nevertheless, the effect of activated sludge on surface morphology and separation performance of the CTA membrane was notable after seven months of continuous exposure. Membrane degradation due to prolonged exposure to activated sludge was manifested by a discernible increase in the average pore size, water and salt permeability, and structural parameter of the CTA membrane. As a result, the initial water flux and reverse salt flux of the CTA membrane after biomass exposure increased; while its capacity for TrOC rejection decreased considerably. These results suggest that current commercially available CTA and polyamide TFC FO membranes may not be readily compatible for long-term OMBR operation. Thus, the realisation of practical OMBR applications will require novel FO membrane materials that can sustain prolonged operation in the biological reactors.

\section{Acknowledgements}

This research was supported under Australian Research Council’s Discovery Project funding scheme (project DP140103864). Wenhai Luo would like to thank the Chinese Scholarship Council and the University of Wollongong for PhD scholarship support. Mr. Hung Duong is thanked for his assistance with SEM measurement. Dr. Jinguo Kang is acknowledged for his assistance for TrOC analysis.

\section{References}

[1] M.A. Shannon, P.W. Bohn, M. Elimelech, J.G. Georgiadis, B.J. Mariñas, A.M. Mayes. Science and technology for water purification in the coming decades, Nature 452 (2008) 301-310.

[2] A. Achilli, T.Y. Cath, E.A. Marchand, A.E. Childress. The forward osmosis membrane bioreactor: A low fouling alternative to MBR processes, Desalination 239 (2009) 10-21.

[3] N.C. Nguyen, S.S. Chen, H.T. Nguyen, H.H. Ngo, W. Guo, C.W. Hao, P.H. Lin. Applicability of a novel osmotic membrane bioreactor using a specific draw solution in wastewater treatment, Sci. Total Environ. 518-519 (2015) 586-594.

[4] E.R. Cornelissen, D. Harmsen, E.F. Beerendonk, J.J. Qin, H. Oo, K.F. de Korte, J.W.M.N. Kappelhof. The innovative osmotic membrane bioreactor (OMBR) for reuse of wastewater, Water Sci. Technol. 63 (2011) 1557-1565.

[5] L. Chen, Y. Gu, C. Cao, J. Zhang, J.-W. Ng, C. Tang. Performance of a submerged anaerobic membrane bioreactor with forward osmosis membrane for low-strength wastewater treatment, Water Res. 50 (2014) 114-123. 
[6] A. Alturki, J. McDonald, S.J. Khan, F.I. Hai, W.E. Price, L.D. Nghiem. Performance of a novel osmotic membrane bioreactor (OMBR) system: Flux stability and removal of trace organics, Bioresour. Technol. 113 (2012) 201-206.

[7] Y. Luo, W. Guo, H.H. Ngo, L.D. Nghiem, F.I. Hai, J. Zhang, S. Liang, X.C. Wang. A review on the occurrence of micropollutants in the aquatic environment and their fate and removal during wastewater treatment, Sci. Total Environ. 473-474 (2014) 619-641.

[8] R.W. Holloway, J. Regnery, L.D. Nghiem, T.Y. Cath. Removal of trace organic chemicals and performance of a novel hybrid ultrafiltration-osmotic membrane bioreactor, Environ. Sci. Technol. 48 (2014) 10859-10868.

[9] W. Luo, F.I. Hai, J. Kang, W.E. Price, L.D. Nghiem, M. Elimelech. The role of forward osmosis and microfiltration in an integrated osmotic-microfiltration membrane bioreactor system, Chemosphere 136 (2015) 125-132.

[10] W. Luo, F.I. Hai, W.E. Price, L.D. Nghiem. Water extraction from mixed liquor of an aerobic bioreactor by forward osmosis: Membrane fouling and biomass characteristics assessment, Sep. Purif. Technol. 145 (2015) 56-62.

[11] R.W. Holloway, A. Achilli, T.Y. Cath. The osmotic membrane bioreactor: A critical review, Environ. Sci. Water Res. Technol. 1 (2015) 581-605.

[12] M. Xie, L.D. Nghiem, W.E. Price, M. Elimelech. A forward osmosis-membrane distillation hybrid process for direct sewer mining: System performance and limitations, Environ. Sci. Technol. 47 (2013) 13486-13493.

[13] C.H. Tan, H.Y. Ng. A novel hybrid forward osmosis - nanofiltration (FO-NF) process for seawater desalination: Draw solution selection and system configuration, Desalin. Water Treat. 13 (2010) 356-361.

[14] O.A. Bamaga, A. Yokochi, B. Zabara, A.S. Babaqi. Hybrid FO/RO desalination system: Preliminary assessment of osmotic energy recovery and designs of new FO membrane module configurations, Desalination 268 (2011) 163-169.

[15] N.T. Hancock, P. Xu, D.M. Heil, T.Y. Cath, C. Bellona. Comprehensive bench- and pilot-scale investigation of trace organic compounds rejection by forward osmosis, Environ. Sci. Technol. 45 (2011) 8483-8490.

[16] L. Chekli, S. Phuntsho, J.E. Kim, J. Kim, J.Y. Choi, J.-S. Choi, S. Kim, J.H. Kim, S. Hong, J. Sohn, H.K. Shon. A comprehensive review of hybrid forward osmosis systems: Performance, applications and future prospects, J. Membr. Sci. 497 (2016) 430-449.

[17] D.L. Shaffer, J.R. Werber, H. Jaramillo, S. Lin, M. Elimelech. Forward osmosis: Where are we now?, Desalination 356 (2015) 271-284. 
[18] T.Y. Cath, A.E. Childress, M. Elimelech. Forward osmosis: Principles, applications, and recent developments, J. Membr. Sci. 281 (2006) 70-87.

[19] C. Liu, W.X. Fang, S.R. Chou, L. Shi, A.G. Fane, R. Wang. Fabrication of layer-bylayer assembled FO hollow fiber membranes and their performances using low concentration draw solutions, Desalination 308 (2013) 147-153.

[20] L. Setiawan, R. Wang, L. Shi, K. Li, A.G. Fane. Novel dual-layer hollow fiber membranes applied for forward osmosis process, J. Membr. Sci. 421-422 (2012) 238-246.

[21] P. Xiao, Y. Yin, X.M. Li, M. Zhang, G. Chen, J. Song, T. He, L.D. Nghiem. A sacrificial-layer approach to fabricate polysulfone support for forward osmosis thin-film composite membranes with reduced internal concentration polarisation, J. Membr. Sci. 481 (2015) 106-114.

[22] A.G. Fane, R. Wang, M.X. Hu. Synthetic membranes for water purification: Status and future, Angew. Chem. Int. Ed. 54 (2015) 3368-3386.

[23] J.R. McCutcheon, M. Elimelech. Influence of membrane support layer hydrophobicity on water flux in osmotically driven membrane processes, J. Membr. Sci. 318 (2008) 458466.

[24] J. Ren, J.R. McCutcheon. A new commercial thin film composite membrane for forward osmosis, Desalination 343 (2014) 187-193.

[25] T.Y. Cath, M. Elimelech, J.R. McCutcheon, R.L. McGinnis, A. Achilli, D. Anastasio, A.R. Brady, A.E. Childress, I.V. Farr, N.T. Hancock, J. Lampi, L.D. Nghiem, M. Xie, N.Y. Yip. Standard methodology for evaluating membrane performance in osmotically driven membrane processes, Desalination 312 (2013) 31-38.

[26] M. Xie, L.D. Nghiem, W.E. Price, M. Elimelech. Relating rejection of trace organic contaminants to membrane properties in forward osmosis: Measurements, modelling and implications, Water Res. 49 (2014) 265-274.

[27] S. Zhao, L. Zou, C.Y. Tang, D. Mulcahy. Recent developments in forward osmosis: Opportunities and challenges, J. Membr. Sci. 396 (2012) 1-21.

[28] A.P. Murphy, C.D. Moody, R.L. Riley, S.W. Lin, B. Murugaverl, P. Rusin. Microbiological damage of cellulose acetate RO membranes, J. Membr. Sci. 193 (2001) 111-121.

[29] J.H. Choi, K. Fukushi, K. Yamamoto. A submerged nanofiltration membrane bioreactor for domestic wastewater treatment: the performance of cellulose acetate nanofiltration membranes for long-term operation, Sep. Purif. Technol. 52 (2007) 470-477. 
[30] A.M. Farooque, A. Al-Amoudi, K. Numata. Degradation study of cellulose triacetate hollow fine-fiber SWRO membranes, Desalination 123 (1999) 165-171.

[31] W. Luo, F.I. Hai, W.E. Price, W. Guo, H.H. Ngo, K. Yamamoto, L.D. Nghiem. High retention membrane bioreactors: Challenges and opportunities, Bioresour. Technol. 167 (2014) 539-546.

[32] J.H. Choi, K. Fukushi, K. Yamamoto, Comparison of treatment efficiency of submerged nanofiltration membrane bioreactors using cellulose triacetate and polyamide membrane. Water Sci. Technol. Vol. 51. 2005. 305-312.

[33] N. Yamano, A. Nakayama, N. Kawasaki, N. Yamamoto, S. Aiba. Mechanism and characterization of polyamide 4 degradation by Pseudomonas sp, J. Polym. Environ. 16 (2008) 141-146.

[34] I. Sutzkover, D. Hasson, R. Semiat. Simple technique for measuring the concentration polarization level in a reverse osmosis system, Desalination 131 (2000) 117-127.

[35] L.D. Nghiem, A.I. Schafer, M. Elimelech. Removal of natural hormones by nanofiltration membranes: Measurement, modeling, and mechanisms, Environ. Sci. Technol. 38 (2004) 1888-1896.

[36] S. Loeb, L. Titelman, E. Korngold, J. Freiman. Effect of porous support fabric on osmosis through a Loeb-Sourirajan type asymmetric membrane, J. Membr. Sci. 129 (1997) 243-249.

[37] L.D. Nghiem, A.I. Schäfer, M. Elimelech. Nanofiltration of hormone mimicking trace organic contaminants, Sep. Sci. Technol. 40 (2005) 2633-2649.

[38] P.M. Bungay, H. Brenner. The motion of a closely-fitting sphere in a fluid-filled tube, Int. J. Multiphase Flow 1 (1973) 25-56.

[39] M. Elimelech, W.H. Chen, J.J. Waypa. Measuring the zeta (electrokinetic) potential of reverse osmosis membranes by a streaming potential analyzer, Desalination 95 (1994) 269-286.

[40] F.I. Hai, K. Tessmer, L.N. Nguyen, J. Kang, W.E. Price, L.D. Nghiem. Removal of micropollutants by membrane bioreactor under temperature variation, J. Membr. Sci. 383 (2011) 144-151.

[41] P. Stoodley, K. Sauer, D.G. Davies, J.W. Costerton. Biofilms as complex differentiated communities Annu. Rev. Microbiol. 56 (2002) 187-209.

[42] J.W. Sowards, E. Mansfield. Corrosion of copper and steel alloys in a simulated underground storage-tank sump environment containing acid-producing bacteria, Corros. Sci. 87 (2014) 460-471. 
[43] B.D. Coday, C. Hoppe-Jones, D. Wandera, J. Shethji, J. Herron, K. Lampi, S.A. Snyder, T.Y. Cath. Evaluation of the transport parameters and physiochemical properties of forward osmosis membranes after treatment of produced water, J. Membr. Sci. 499 (2016) 491-502.

[44] L. Huang, J.R. McCutcheon. Impact of support layer pore size on performance of thin film composite membranes for forward osmosis, J. Membr. Sci. 483 (2015) 25-33.

[45] Z. Wang, J. Tang, C. Zhu, Y. Dong, Q. Wang, Z. Wu. Chemical cleaning protocols for thin film composite (TFC) polyamide forward osmosis membranes used for municipal wastewater treatment, J. Membr. Sci. 475 (2015) 184-192.

[46] M. Xie, M. Zheng, P. Cooper, W.E. Price, L.D. Nghiem, M. Elimelech. Osmotic dilution for sustainable greenwall irrigation by liquid fertilizer: Performance and implications, J. Membr. Sci. 494 (2015) 32-38.

[47] B. Mi, M. Elimelech. Gypsum scaling and cleaning in forward osmosis: Measurements and mechanisms, Environ. Sci. Technol. 44 (2010) 2022-2028.

[48] B.D. Coday, B.G.M. Yaffe, P. Xu, T.Y. Cath. Rejection of trace organic compounds by forward osmosis membranes: A literature review, Environ. Sci. Technol. 48 (2014) 36123624.

[49] N. Tadkaew, F.I. Hai, J.A. McDonald, S.J. Khan, L.D. Nghiem. Removal of trace organics by MBR treatment: The role of molecular properties, Water Res. 45 (2011) 2439-2451.

[50] A.A. Alturki, J.A. McDonald, S.J. Khan, W.E. Price, L.D. Nghiem, M. Elimelech. Removal of trace organic contaminants by the forward osmosis process, Sep. Purif. Technol. 103 (2013) 258-266.

[51] L.D. Nghiem, A.I. Schäfer, M. Elimelech. Role of electrostatic interactions in the retention of pharmaceutically active contaminants by a loose nanofiltration membrane, $\mathrm{J}$. Membr. Sci. 286 (2006) 52-59.

[52] M. Xie, L.D. Nghiem, W.E. Price, M. Elimelech. Comparison of the removal of hydrophobic trace organic contaminants by forward osmosis and reverse osmosis, Water Res. 46 (2012) 2683-2692.

[53] M. Xie, W.E. Price, L.D. Nghiem. Rejection of pharmaceutically active compounds by forward osmosis: Role of solution $\mathrm{pH}$ and membrane orientation, Sep. Purif. Technol. 93 (2012) 107-114. 


\section{LIST OF FIGURE}

Pristine CTA

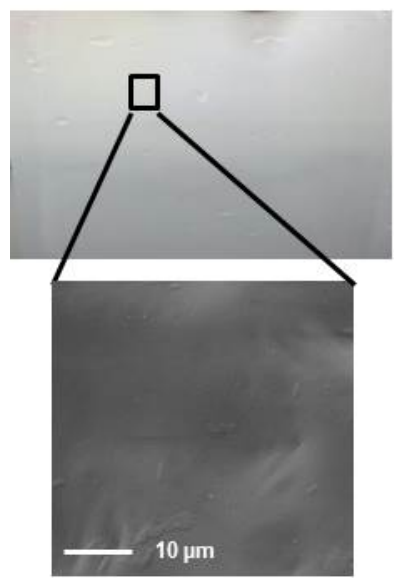

Exposed CTA

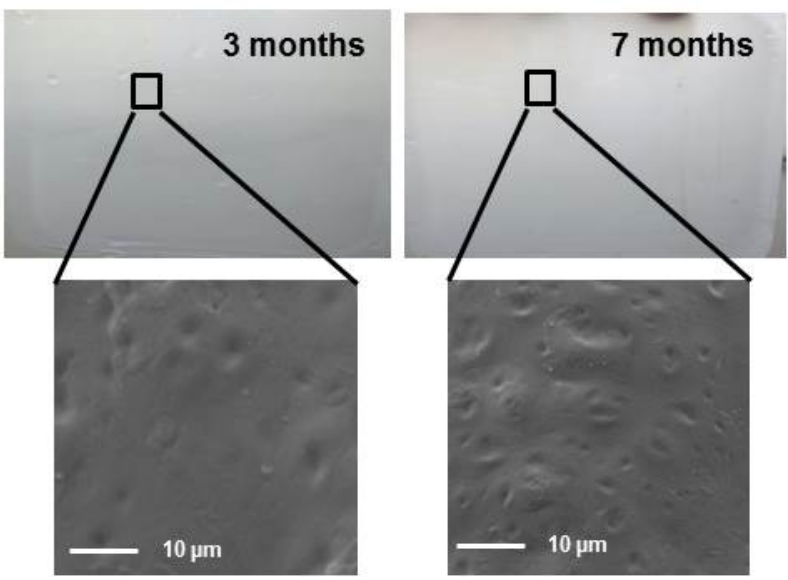

Figure 1: Photos and SEM micrographs of the active layer of the pristine and exposed CTA membranes. Exposed membranes were obtained after their suspension in an activated sludge bioreactor for 3 and 7 months.
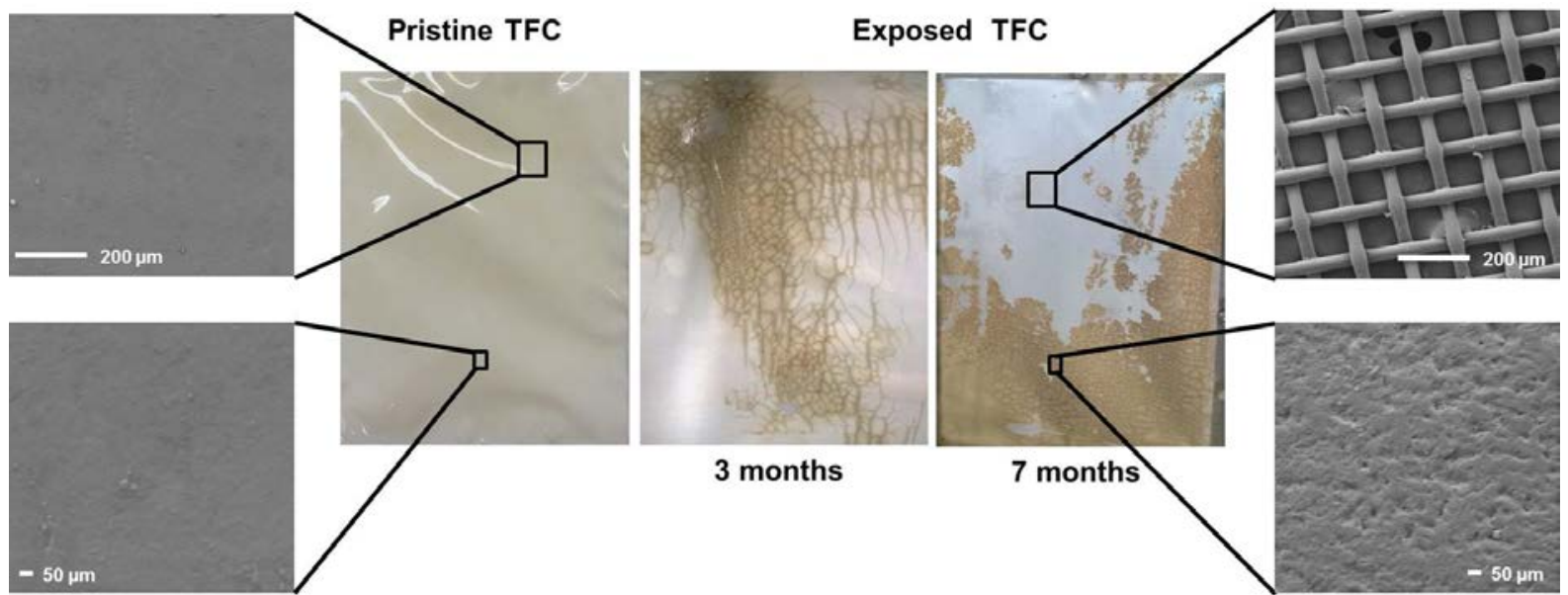

Figure 2: Photos and SEM micrographs of the active layer of the pristine and exposed TFC membranes. Exposed membranes were obtained after their suspension in an activated sludge bioreactor for 3 and 7 months. 


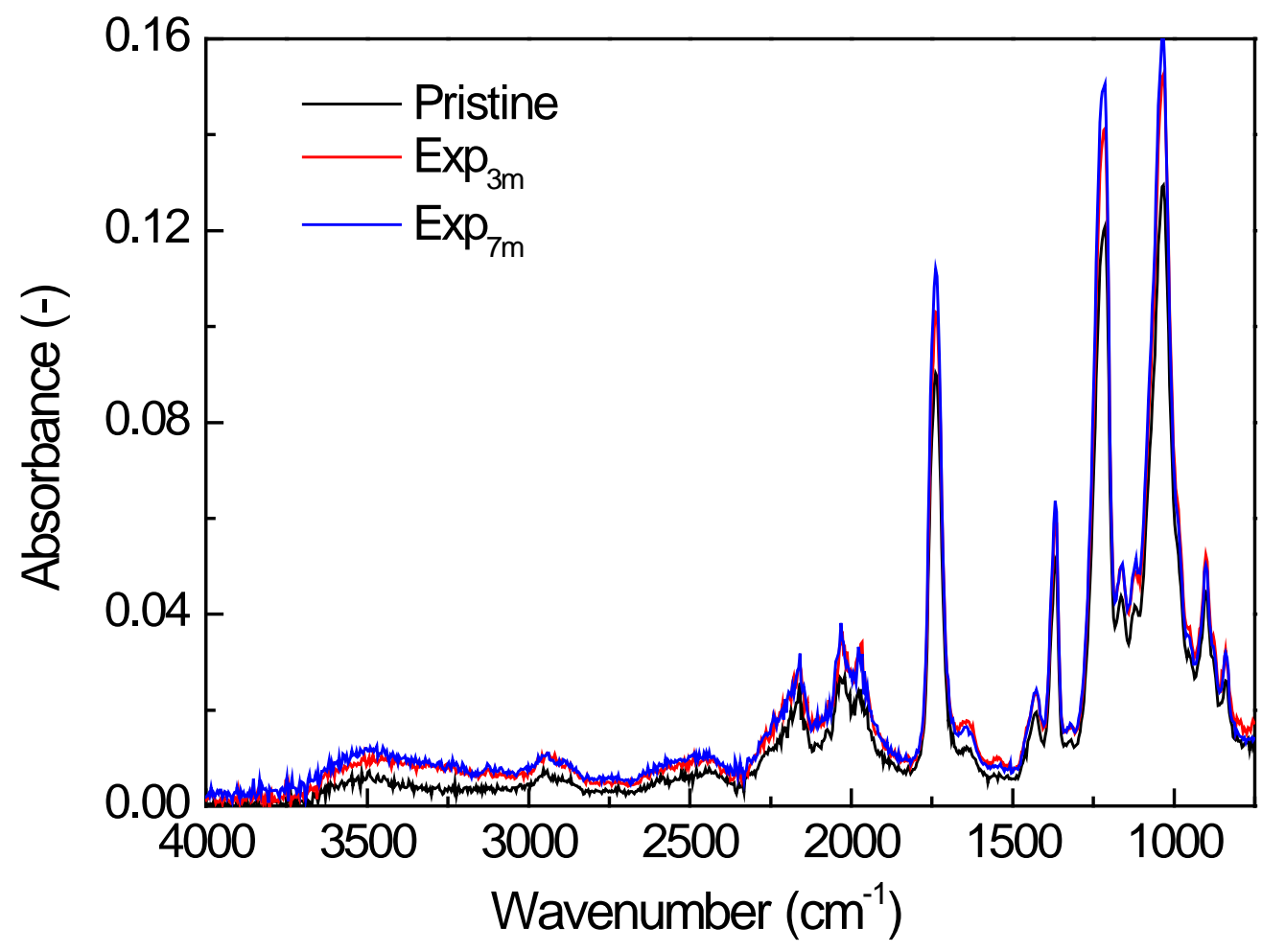

Figure 3: ATR-FTIR absorption spectra of the active layer of the pristine and exposed CTA FO membranes. $\operatorname{Exp}_{3 \mathrm{~m}}$ and $\operatorname{Exp}_{7 \mathrm{~m}}$ were membrane samples exposed to an activated sludge bioreactor for 3 and 7 months, respectively. 

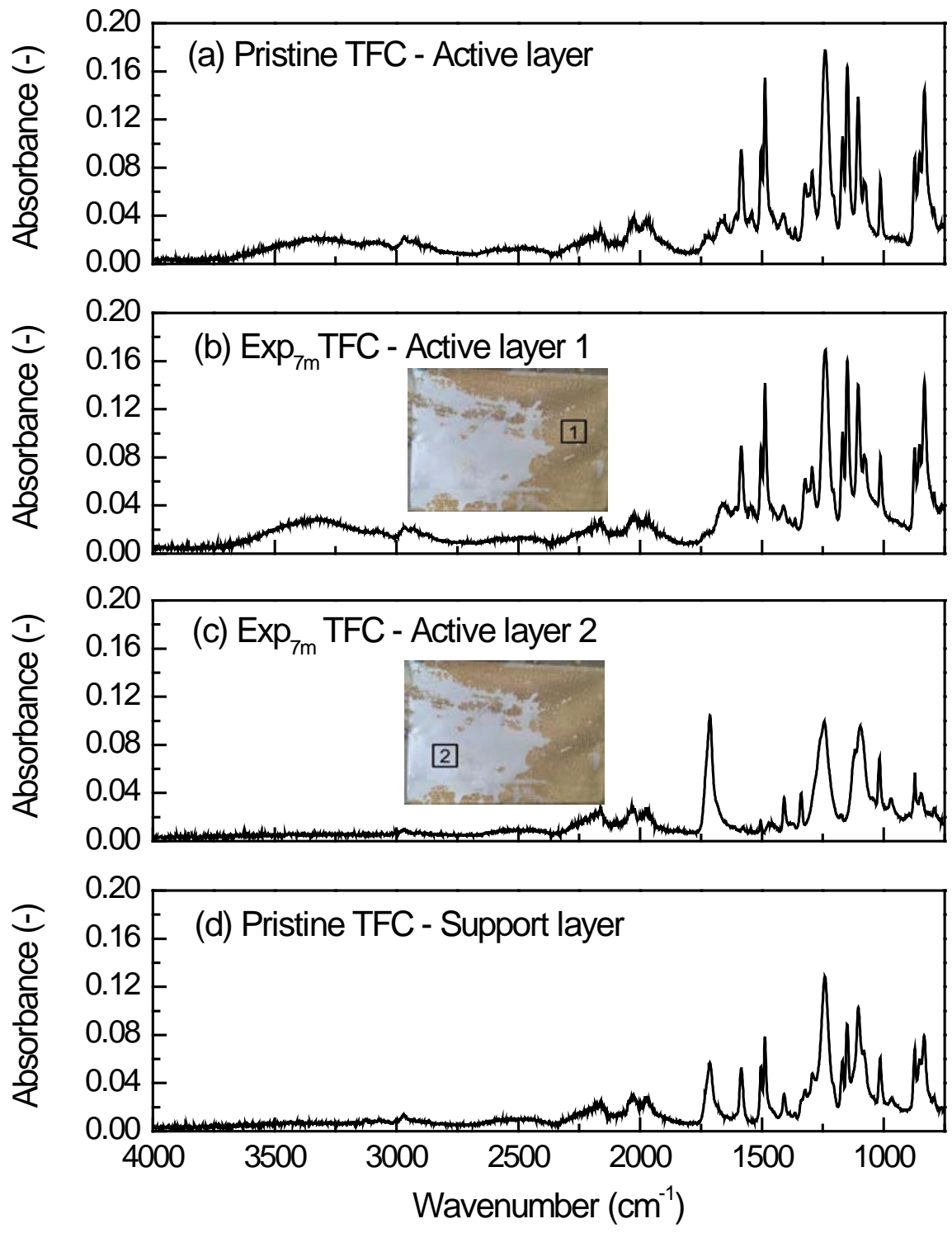

Figure 4: ATR-FTIR absorption spectra of the pristine and exposed TFC FO membranes. $\operatorname{Exp}_{7 \mathrm{~m}}$ TFC was the membrane sample exposed to an activated sludge bioreactor for 7 months. Active layer 1 and 2 were coupons (shown in the attached photos) cut from the exposed membrane for measurement. 


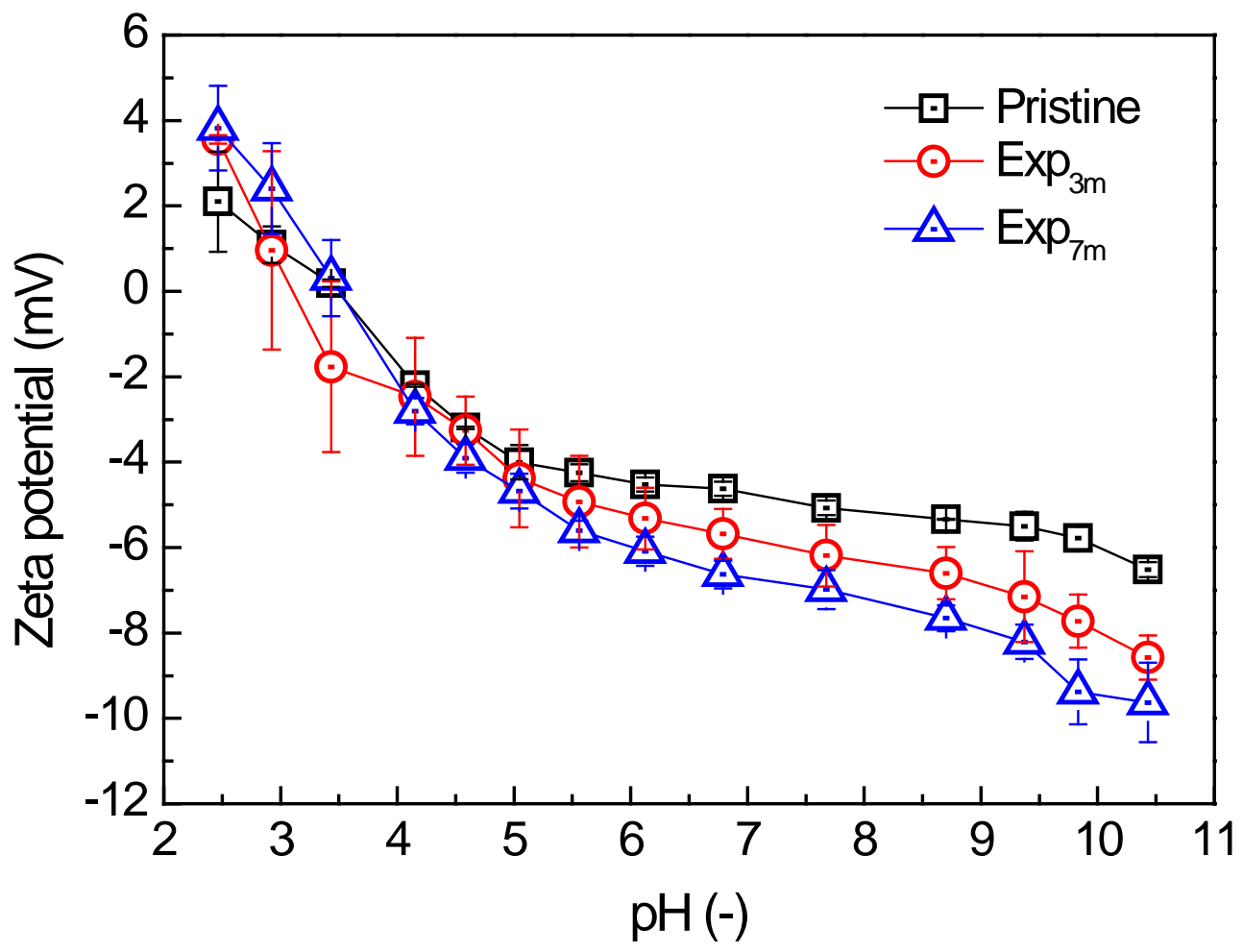

Figure 5: Zeta potential of the active layer of pristine and exposed CTA membranes as a function of solution $\mathrm{pH}$. $\operatorname{Exp}_{3 \mathrm{~m}}$ and $\operatorname{Exp}_{7 \mathrm{~m}}$ were membrane samples exposed to an activated sludge bioreactor for 3 and 7 months, respectively. Zeta potential measurements were conducted using a background electrolyte solution $(10 \mathrm{mM} \mathrm{KCl})$ in a temperature-controlled room $\left(22 \pm 1^{\circ} \mathrm{C}\right)$. Error bars represent standard deviation from four replicate measurements of two samples for each membrane. 


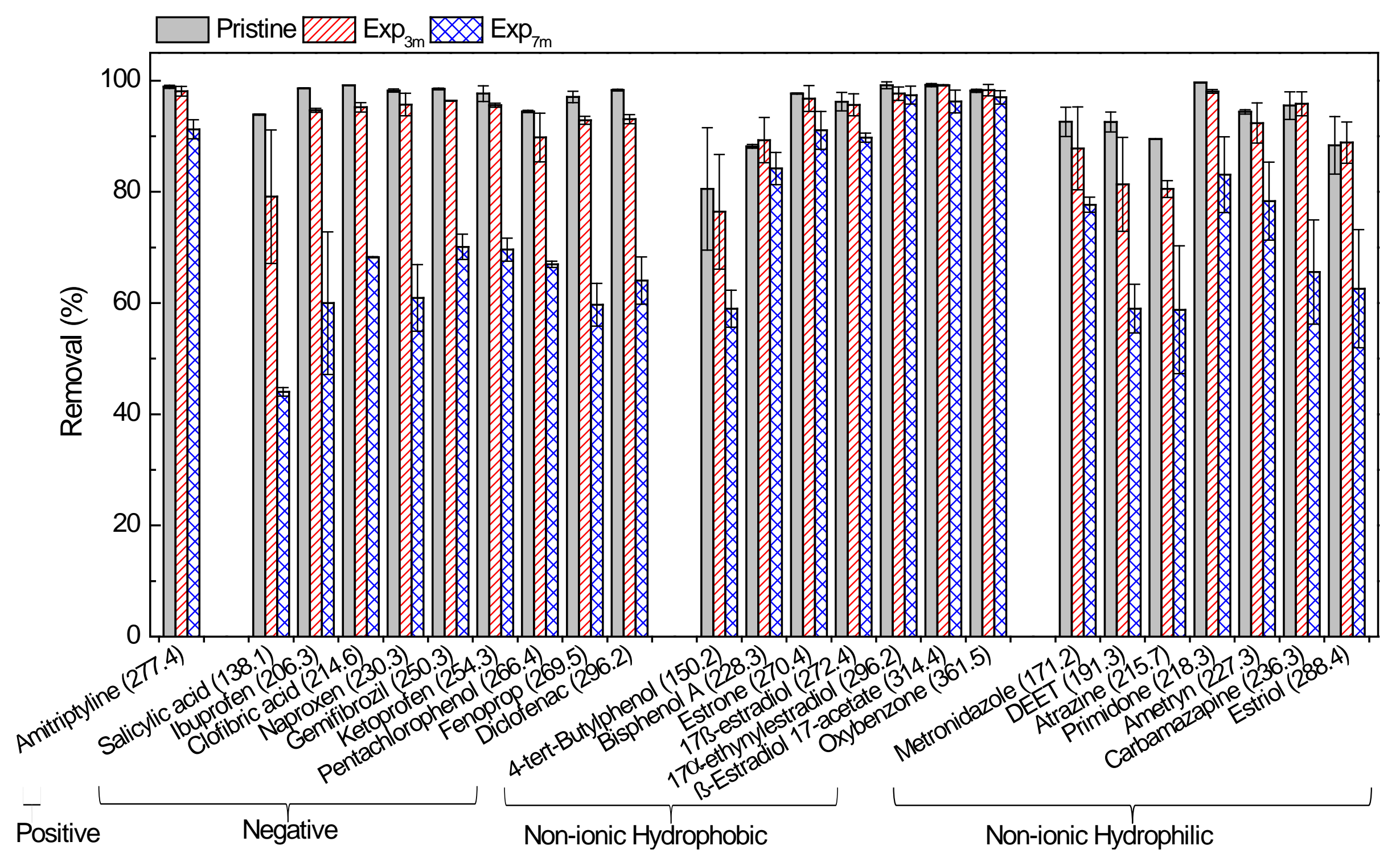


Figure 6: TrOC rejection by the pristine and exposed CTA membranes in FO operation. Exp $3 \mathrm{~m}$ and Exp7m were membrane samples exposed to an activated sludge bioreactor for 3 and 7 months, respectively. Molecular weight (g/mol) of each compound is shown in the parenthesis. Based on their Log $D$ values (effective octanol-water partition coefficient) at solution pH 8, non-ionic compounds were grouped as hydrophilic (Log $\left.D_{\mathrm{pH} 7}<3.2\right)$ and hydrophobic ( $\left.\log D_{\mathrm{pH} 7}>3.2\right)$. Experimental conditions: FO mode; feed = electrolyte solution $\left(1 \mathrm{mM} \mathrm{NaHCO}_{3}\right.$ and $20 \mathrm{mM}$ $\mathrm{NaCl}$ ) containing $5 \mu \mathrm{g} / \mathrm{L}$ of each TrOC; draw $=1 \mathrm{M} \mathrm{NaCl}$ solution; temperature $=22 \pm 1{ }^{\circ} \mathrm{C}$. Error bars represent standard deviation from two replicate measurements of each membrane sample. 


\section{LIST OF TABLE}

Table 1: Mass transport parameters of the pristine and exposed CTA FO membranes (average \pm standard deviation from duplication experiments).

\begin{tabular}{cccc}
\hline Membrane & Pristine & $\operatorname{Exp}_{3 \mathrm{~m}}$ & $\operatorname{Exp}_{7 \mathrm{~m}}$ \\
\hline $\begin{array}{c}\text { Pure water permeability } \\
\text { coefficient, } A\left(\mathrm{~L} \mathrm{~m}^{-2} \mathrm{~h}^{-1} \mathrm{bar}^{-1}\right)\end{array}$ & $0.84 \pm 0.03$ & $1.06 \pm 0.02$ & $1.29 \pm 0.04$ \\
$\begin{array}{c}\text { Salt }(\mathrm{NaCl}) \text { permeability } \\
\text { coefficient, } B\left(\mathrm{~L} \mathrm{~m}^{-2} \mathrm{~h}^{-1}\right)\end{array}$ & $0.32 \pm 0.06$ & $1.09 \pm 0.15$ & $4.80 \pm 0.25$ \\
Membrane structural & $0.57 \pm 0.02$ & $0.61 \pm 0.01$ & $0.79 \pm 0.06$ \\
parameter, $S(\mathrm{~mm})$ & & & \\
\hline
\end{tabular}

Table 2: Estimated average membrane pore radii of the pristine and exposed CTA FO membranes.

\begin{tabular}{ccccc}
\hline Membrane & Organic solute & Solute size $r_{s}(\mathrm{~nm})$ & $\lambda=r_{s} / r_{p}$ & Pore radius $r_{p}(\mathrm{~nm})$ \\
\hline \multirow{4}{*}{ Pristine } & Erythitol & 0.26 & 0.84 & 0.31 \\
& Xylose & 0.29 & 0.86 & 0.34 \\
& Glucose & 0.32 & 0.89 & 0.36 \\
\cline { 2 - 5 } & Average & & 0.77 & $0.34 \pm 0.02$ \\
\hline \multirow{5}{*}{$\operatorname{Exp}_{3 \mathrm{~m}}$} & Erythitol & 0.26 & 0.34 \\
& Xylose & 0.29 & 0.79 & 0.37 \\
& Glucose & 0.32 & 0.83 & 0.39 \\
\cline { 2 - 5 } $\operatorname{Exp}_{7 \mathrm{~m}}$ & Average & & & $0.36 \pm 0.02$ \\
& Erythitol & 0.26 & 0.62 & 0.42 \\
& Xylose & 0.29 & 0.63 & 0.46 \\
& Glucose & 0.32 & 0.63 & 0.51 \\
\cline { 2 - 5 } & Average & & $0.46 \pm 0.04$ \\
\hline
\end{tabular}


Table 3: Contact angle of the active and supporting layers of the pristine and exposed CTA FO membranes (average \pm standard deviation from repetitive measurements at 10 different locations).

\begin{tabular}{ccc}
\hline Membrane & Active layer $\left(^{\circ}\right)$ & Supporting layer $\left(^{\circ}\right)$ \\
\hline Pristine & $61 \pm 2$ & $69 \pm 5$ \\
Exp $_{3 m}$ & $77 \pm 4$ & $83 \pm 3$ \\
Exp $_{7 m}$ & $73 \pm 2$ & $84 \pm 3$ \\
\hline
\end{tabular}

